\title{
ANALISIS PENILAIAN KONSUMEN TERHADAP EKUITAS MEREK COFFEE SHOPS DI SURABAYA
}

\author{
Maya Widjaja \\ Alumnus Program Manajemen Perhotelan, Fakultas Ekonomi, Universitas Kristen Petra \\ Serli Wijaya \\ Dosen Program Manajemen Perhotelan, Fakultas Ekonomi, Universitas Kristen Petra \\ Email: serliw@peter.petra.ac.id \\ Regina Jokom \\ Mahasiswa Program Manajemen Perhotelan, Fakultas Ekonomi, Universitas Kristen Petra \\ (saat ini menempuh Double Degree Program di Stenden University, the Netherland) \\ E-mail: egi_smile@yahoo.com
}

\begin{abstract}
Abstrak: Penelitian ini bertujuan untuk mengukur ekuitas merek empat coffee shops di Surabaya, yaitu Excelso, DOME, Starbucks dan Coffee Bean \& Tea Leaf. Ekuitas merek diukur berdasarkan 4 variabel dari Aaker yaitu kesadaran merek, asosiasi merek, kesan kualitas dan loyalitas merek. Hasil penelitian terungkap bahwa Starbucks merupakan coffee shop yang kesadaran mereknya paling banyak diingat oleh responden, diasosiasikan paling positif dan loyalitas mereknya paling tinggi. Sedangkan Excelso merupakan coffee shop dengan kesan kualitas paling baik.
\end{abstract}

Kata kunci: kesadaran merek, asosiasi merek, kesan kualitas, loyalitas merek, coffee shop

\begin{abstract}
This research aims to examine brand equity of four coffee shops in Surabaya, they are Excelso, DOME, Starbucks dan Coffee Bean \& Tea Leaf. Brand equity is measured based on variables developed by Aaker, namely brand awareness, brand association, perceived quality and brand loyalty. The result shows that Starbucks achieves the highest top of mind of brand awareness, has the best brand association in consumers' image, and has the strongest brand loyalty; while Excelso has the best perceived quality.
\end{abstract}

Keywords: brand awareness, brand association, perceived quality, brand loyalty, coffee shop

Merek bukan hanya sebuah nama, simbol, gambar atau tanda yang tidak berarti. Merek merupakan identitas sebuah produk yang dapat dijadikan sebagai alat ukur apakah produk itu baik dan berkualitas. Konsumen melihat sebuah merek sebagai bagian yang paling penting dalam sebuah produk, dan merek dapat menjadi sebuah nilai tambah dalam produk tersebut (Kotler, 2004, p. 285). Karena itu merek merupakan aset penting dalam sebuah bisnis. Meskipun merek bersifat intangible, tapi nilai sebuah merek lebih dari pada sesuatu yang tangible.

Merek tidak berkembang terbatas pada produk barang saja, tetapi juga produk jasa dan juga bisnis yang menghasilkan produk barang sekaligus jasa. Untuk bisnis yang menjual paduan antara barang dan jasa misalnya bisnis HORECA (Hotel, Restaurant and Cafe). Bagi konsumen, bisnis HORECA yang mempunyai merek kuat, dapat memberikan nilai lebih pada konsumennya. Dari segi sosial, itu dapat memberikan pengaruh nilai emosional yaitu prestige konsumen.
Seiring dengan berkembangnya jaman, masyarakat kota pada saat ini mengalami perubahan gaya hidup (lifestyle). Salah satu manifestasi gaya hidup modern saat ini adalah kebiasaan kelompok masyarakat tertentu yang nongkrong di cafe atau coffee shops. Bisnis coffee shop mengalami perkembangan, dimana di hampir semua shopping mall utama di Surabaya terdapat empat coffee shop yang perkembangannya lebih dominan dibandingkan merek lain yaitu Coffee Bean \& Tea Leaf (dari Amerika), Dome (dari Australia), serta merek lokal seperti Kafe Excelso.

Dari fenomena di atas peneliti ingin mengetahui bagaimana penilaian konsumen Surabaya terhadap perkembangan bisnis coffee shop tersebut diukur dari ekuitas mereknya. Ekuitas merek adalah seperangkat aset dan liabilitas merek yang berkaitan dengan suatu merek, nama dan simbolnya, yang menambah atau mengurangi nilai yang diberikan oleh suatu barang dan jasa kepada perusahaan atau pelanggan. Menurut Aaker, ekuitas merek diukur melalui empat dimensi 
yaitu brand awareness, brand association, perceived quality dan brand loyalty (1991, p. 62).

\section{TEORI PENUNJANG}

\section{Konsep Ekuitas Merek (Brand Equity)}

Ekuitas merek adalah seperangkat aset dan liabilitas merek yang berkaitan dengan suatu merek, nama dan simbolnya, yang menambah atau mengurangi nilai yang diberikan oleh suatu barang dan jasa kepada perusahaan atau pelanggan. Menurut Aaker (2001, p.165), ekuitas merek dapat dikelompokkan dalam 5 kategori:

1. Kesadaran Merek (Brand Awareness)

2. Asosiasi Merek (Brand Associations)

3. Persepsi Kualitas (Perceived Quality)

4. Loyalitas merek (Brand Loyalty)

5. Aset-aset hak milik merek yang lain, mewakili aset merek seperti paten, dan saluran distribusi.

\section{Kesadaran Merek (Brand Awareness)}

Aaker (1991, p. 60) mendefinisikan kesadaran merek adalah kesanggupan seorang calon pembeli untuk mengenali atau mengingat kembali bahwa suatu merek merupakan bagian dari kategori merek tertentu.

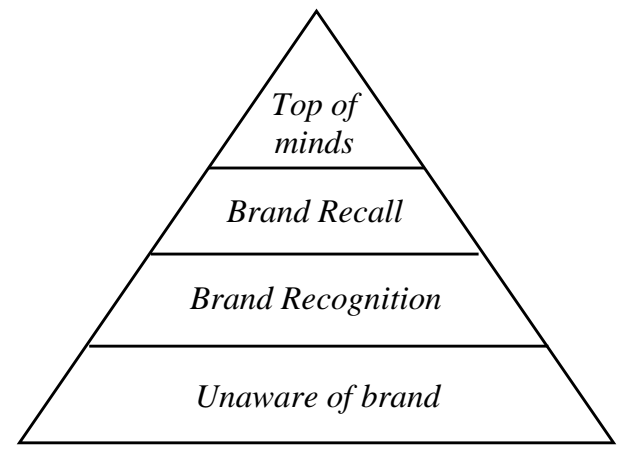

Sumber: Aaker, 1991, p.62

\section{Gambar 1. Piramida Kesadaran Merek (The Awareness Pyramid)}

\section{Asosiasi Merek (Brand Association)}

Menurut Aaker (2001, p. 167) asosiasi merek adalah segala sesuatu yang berkaitan secara langsung maupun tidak langsung dengan ingatan konsumen terhadap suatu merek. Ditambahkan oleh Susanto (2004, p. 133) hal-hal lain yang penting dalam asosiasi merek adalah asosiasi yang menunjukan fakta bahwa produk dapat digunakan untuk mengekspresikan gaya hidup, kelas sosial, dan peran professional; atau, yang mengekspresikan asosiasi-asosiasi yang memerlukan aplikasi produk dan tipe-tipe orang yang menggunakan produk tersebut, toko yang menjual produk atau wiraniaganya.

Lebih lanjut Aaker (1991, p. 115) menjelaskan bahwa asosiasi-asosiasi yang terkait dengan suatu merek dapat dihubungkan dengan berbagai hal berikut :

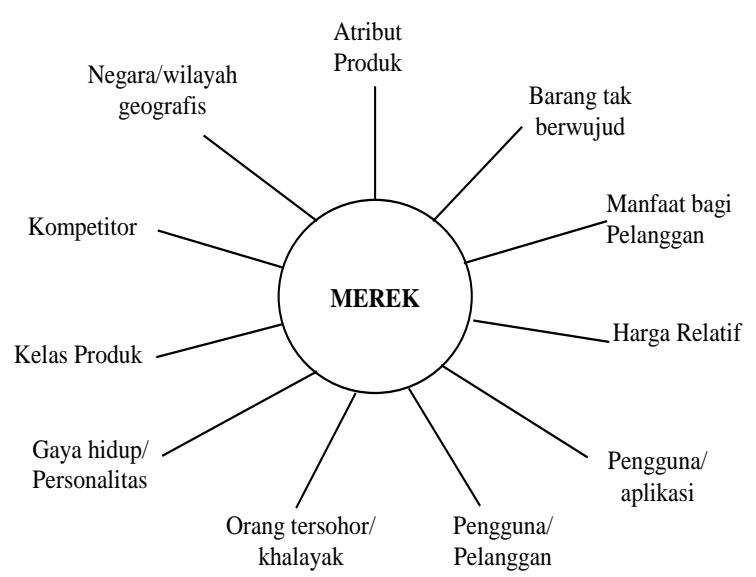

Sumber : Aaker, 1991, p.115

\section{Gambar 2. Types of Association}

\section{Kesan Kualitas (Perceived Quality)}

Menurut Susanto (2004, p.129), kesan kualitas dapat didefinisikan sebagai persepsi pelanggan terhadap keseluruhan kualitas atau keungulan suatu produk atau jasa berkenaan dengan maksud yang diharapkan. Lebih lanjut, menurut Aaker (1991, p. 91), apabila kesan kualitas adalah untuk dimengerti dan diatur, maka penting untuk mengetahui dimensidimensi yang mempengaruhi kesan kualitas produk dan kualitas jasa, yaitu:

1. Kualitas produk, terbagi menjadi:

a. Performance-karakteristik operasional produk yang utama.

b. Features-elemen sekunder dari produk atau bagian tambahan dari produk.

c. Conformance with specifications-tidak ada produk yang cacat.

d. Reliability-konsistensi kinerja produk.

e. Durability-daya tahan sebuah produk.

f. Serviceability-kemampuan memberikan pelayanan sehubungan dengan produk.

g. Fit and finish-menunjukkan saat munculnya atau dirasakannya kualitas produk.

2. Sedangkan dimensi kualitas jasa menurut Zeithaml \& Bitner (2003), terbagi menjadi 5 aspek, antara lain:

a. Reliability-kemampuan menampilkan pelayanan yang diandalkan dan akurat.

b. Responsiveness-kesediaan membantu dan menyediakan layanan yang cepat. 
c. Assurance-pengetahuan dan kemampuan karyawan untuk menumbuhkan keyakinan konsumen terhadap pelayanan penyedia jasa.

d. Empathy-menunjukkan perhatian perusahaan terhadap konsumennya.

e. Tangibles-tampilan dari fasilitas fisik, peralatan, personil/karyawan.

\section{Kesetiaan Merek (Brand Loyalty)}

Menurut Ford (2005, p. 132), loyalitas merek dapat dilihat dari seberapa sering orang membeli merek itu dibandingkan dengan merek lainnya.

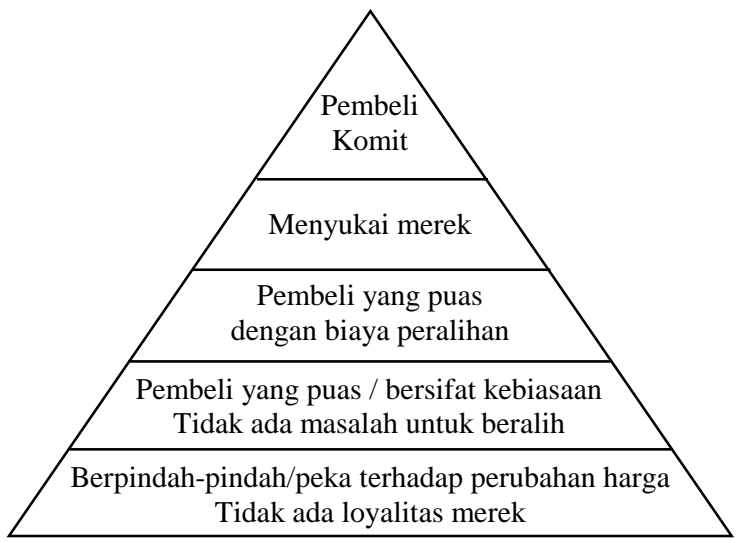

Sumber : Aaker, 1991, p.40

\section{Gambar 3. The Loyalty Pyramid}

Berikut penjelasan Susanto (2004, p. 127-128) tentang tingkatan loyalitas terhadap merek yaitu :

1. Tingkatan yang paling dasar adalah pembeli tidak loyal, yang sama sekali tidak tertarik pada merek tersebut dan bagi mereka merek apapun dianggap memadai sehingga merek memainkan peran yang kecil dalam keputusan pembelian.

2. Tingkat kedua adalah para pembeli yang puas dengan produk atau setidaknya tidak mengalami kepuasan, tipe ini bisa disebut sebagai pembeli kebiasaan (habitual buyer).

3. Tingkat ketiga berisi orang-orang yang puas, namun mereka memikul biaya peralihan (switching cost) serta biaya berupa waktu, uang atau resiko kinerja berkenaan dengan tindakan beralih merek, kelompok ini bisa disebut pelanggan yang loyal terhadap biaya peralihan.

4. Tingkat keempat adalah mereka yang sungguhsungguh menyukai merek tersebut, preferensinya mungkin dilandasi oleh suatu asosiasi seperti simbol, rangkaian pengalaman dalam menggunakan atau persepsi kualitas yang tinggi.

5. Tingkat teratas adalah pelanggan yang setia, mereka mempunyai kebanggaan menjadi pengguna suatu merek, merek tersebut sangat penting bagi mereka, baik dari segi fungsinya maupun sebagai ekspresi diri mereka.

(Susanto, 2004, p.127-128)

\section{Kerangka Pemikiran}

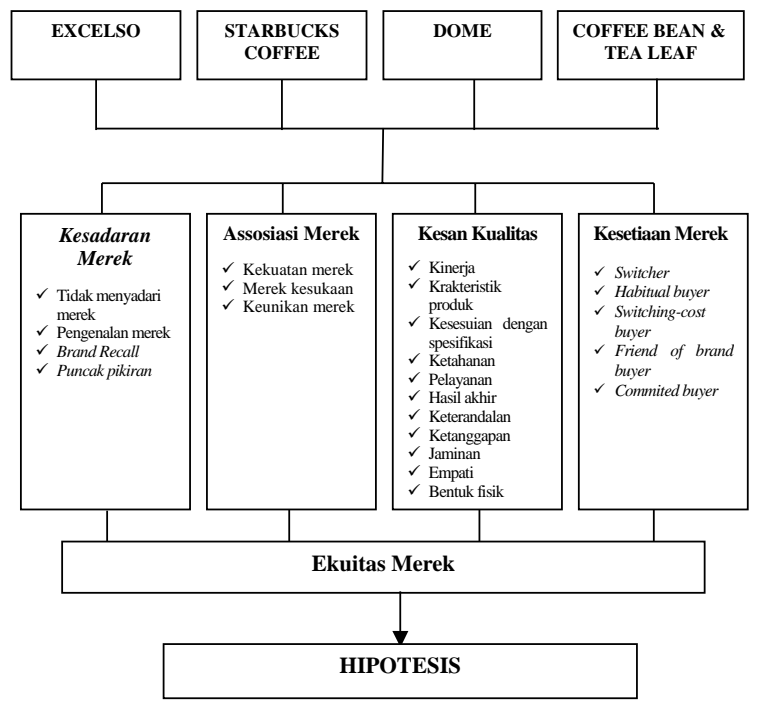

Gambar 4. Kerangka Pemikiran

\section{Hipotesis}

Interbrand dan Business Week melakukan penelitian “Best Global Branding 2006” mengenai merek global terbaik. Berdasarkan penelitian tersebut, Starbucks Coffee menduduki peringkat yang ke-91. Starbucks dinilai mempunyai merek yang baik, dari segi produk, servis, dan konsumen secara internasional. Selain itu, Starbucks merupakan salah satu perusahaan yang memiliki pertumbuhan bisnis tercepat.

Berdasarkan hasil penelitian tersebut, maka untuk penelitian mengenai ekuitas merek coffee shop di Surabaya ini, penulis merumuskan hipotesis sebagai berikut :

1. Starbucks Coffee merupakan coffee shop yang menjadi the top of mind - brand awareness

2. Starbucks Coffee merupakan coffee shop yang menjadi the best of brand associations

3. Starbucks Coffee merupakan coffee shop yang menjadi the best of perceived quality

4. Starbucks Coffee merupakan coffee shop yang menjadi the strongest of brand loyalty

\section{METODE PENELITIAN}

\section{Jenis Penelitian, Gambaran Populasi dan Sampel}

Jenis Penelitian yang digunakan penulis adalah deskriptif kuantitatif karena menggambarkan penilaian konsumen terhadap ekuitas merek coffee shop 
di Surabaya (Kuncoro, 2003, p. 75). Adapun gambaran populasi dalam penelitian ini adalah:

1. Mengenal dan memiliki pengetahuan tentang coffee shop di Surabaya.

2. Kunjungan minimal 3 kali pada salah satu dari keempat coffee shop yang diteliti (Excelso, Starbucks coffee, DOME dan Coffee Bean and Tea Leaf) untuk mengukur kesan kualitas dan loyalitas merek.

3. Berusia antara 20-40 tahun. Mengingat kebanyakan yang menjadi konsumen coffee shop adalah kalangan mahasiswa dan eksekutif muda.

Metode pengambilan sampel yang digunakan peneliti dalam penelitian ini adalah non-probability sampling dan teknik convenience sampling. Dengan 360 responden yang dipilih sebagai sampel. Selain itu, penulis menggunakan teknik quota sampling dengan membagi sampel yang diambil pada masingmasing coffee shop sebanyak 90 responden.

\section{Definisi Operasional Variabel}

\section{Variabel Kesadaran Merek (Brand Awareness)}

Kesanggupan konsumen untuk mengenali atau mengingat kembali bahwa suatu merek merupakan bagian dari kategori merek tertentu. Hasil pengukuran ini dapat dibagi menjadi empat tingkatan, yaitu:

a. Brand recall, definisi operasionalnya adalah merek yang disebut oleh responden tanpa dibantu dengan daftar merek.

b. Brand recognition, definisi operasionalnya adalah merek yang disebut oleh responden setelah dibantu dengan daftar merek yang ada dalam kuisioner.

c. Top of mind, definisi operasionalnya adalah merek yang disebut pertama kali oleh responden.

\section{Variabel Asosiasi Merek (Brand Association)}

Asosiasi merek merupakan segala sesuatu yang berkaitan langsung maupun tidak langsung dengan ingatan konsumen terhadap suatu merek, yakni pencitraan suatu merek yang tercermin dari kesan tertentu sehubungan dengan kebiasaan, gaya hidup, manfaat, atribut produk, geografis, harga, pesaing, selebritis, dan lain-lain.

Dimensi asosiasi merek yaitu:

a. Brand Strength (kekuatan merek), definisi operasionalnya adalah asosiasi yang berhubungan dengan kekuatan coffee shop yang diteliti.

b. Brand Favorability (kesukaan merek), definisi operasionalnya adalah asosiasi yang berhubungan dengan kesukaan terhadap coffee shop yang diteliti yang terbentuk di benak responden. c. Brand Uniqueness (keunikan merek), definisi operasionalnya adalah asosiasi yang berhubungan dengan keunikan merek yang tercipta dari asosiasi strength dan favorability, yang ada di benak responden yang membuat sebuah coffee shop menjadi berbeda dari coffee shop yang lainnya.

d. Variabel Kesan Kualitas (Perceived Quality)

Persepsi pelanggan terhadap keseluruhan kualitas atau keunggulan suatu produk atau jasa berkenaan dengan maksud yang diharapkan.

Tingkatan kesan kualitas diukur melalui 2 dimensi yaitu produk dan servis.

Pada dimensi produk, melalui :

a. Performance, definisi operasionalnya adalah segala sesuatu yang melibatkan berbagai karakteristik operasional produk yang utama.

b. Conformance with specifications (kesesuaian dengan spesifikasi), definisi operasionalnya adalah tidak ada produk yang cacat sehingga merupakan penilaian mengenai kualitas proses pembuatan.

c. Reliability (keterandalan), definisi operasionalnya adalah konsistensi kinerja produk dari satu pembelian hingga pembelian berikutnya dan persentase waktu yang dimiliki produk untuk berfungsi sebagaimana mestinya.

d. Serviceability (pelayanan), definisi operasionalnya adalah kemampuan perusahaan untuk memberikan pelayanan sehubungan dengan produk tersebut.

e. Fit and finish (hasil akhir), definisi operasionalnya adalah saat munculnya atau dirasakannya kualitas produk.

Sedangkan kesan kualitas pada dimensi jasa / servis, diukur melalui :

a. Reliability (keterandalan), definisi operasionalnya adalah kemampuan karyawan untuk menampilkan suatu pelayanan yang dapat diandalkan dan akurat.

b. Responsiveness (ketanggapan), definisi operasionalnya adalah kesediaan karyawan untuk membantu konsumen dan menyediakan pelayanan yang cepat.

c. Assurance (jaminan), definisi operasionalnya adalah pengetahuan dan kemampuan karyawan untuk menumbuhkan keyakinan dan rasa percaya diri konsumen terhadap pelayanan restoran.

d. Empathy (empati), definisi operasionalnya adalah perhatian coffee shop dan karyawannya terhadap konsumennya secara individu. 
e. Tangibles (bentuk fisik), definisi operasionalnya adalah tampilan dari fasilitas fisik, peralatan dan personil atau karyawan.

\section{Variabel Loyalitas Merek (Brand Loyalty)}

Tingkat keterikatan konsumen dengan suatu merek dicerminkan dengan frekuensi pembelian produk suatu merek yang lebih banyak dibandingkan dengan produk yang sama dengan merek lain.

Tingkatan loyalitas merek yaitu:

a. Friend of brand Buyer (pembeli yang menyukai merek), definisi operasionalnya adalah pembeli yang menganggap suatu coffee shop sebagai teman karena pembeli mempunyai asosiasi, pengalaman, atau perceived quality (kesan kualitas) yang tinggi dan terdapat perasaan emosi yang terkait.

b. Committed Buyer (pembeli komit), definisi operasionalnya adalah pembeli yang mempunyai kebanggaan menjadi konsumen dari suatu coffee shop.

\section{ANALISIS DAN PEMBAHASAN}

\section{Analisis Kesadaran Merek Coffee Shop di Surabaya}

Kesadaran Merek - Dimensi Top of Mind

Top of Mind

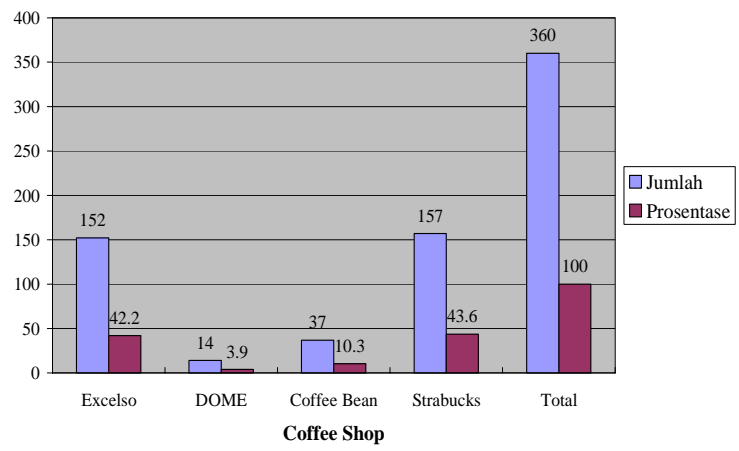

Sumber : Data primer, diolah

Gambar 5. Kesadaraan Merek - Top of Mind
Dari gambar 5 terlihat bahwa Starbucks merupakan coffee shop yang paling banyak disebut pertama kali oleh responden, yaitu sebanyak 43,6\% (sebanyak 157 orang dari total 360 responden). Jadi Starbucks merupakan coffee shop yang menjadi the Top of mind-Brand Awareness. Starbucks mempunyai kekuatan kesadaran merek dimana bagi Starbucks hal tersebut merupakan langkah awal yang baik dalam membangun ekuitas mereknya. Namun yang harus diwaspadai oleh Starbucks adalah keberadaan Excelso sebagai coffee shop lokal yang menduduki Top of Mind ke-dua setelah Starbucks.

Selanjutnya, penulis melakukan analisis tambahan berikut untuk menjelaskan mengenai pertanyaan screening yang terdapat pada kuisioner. Jawaban dari pertanyaan ini menjadi dasar dalam pengisian kuisioner selanjutnya (lembar kedua-kesan kualitas dan loyalitas merek), karena diharapkan responden yang mengisi lembar selanjutnya pernah mengunjungi salah satu coffee shop yang diteliti, minimal 3 kali kedatangan. Input data pertanyaan ini hanya menggunakan jawaban ya atau tidak sesuai dengan top of mind.

Tabel 1 merupakan hasil cross-tabulation antara Top of Mind dengan jawaban pertanyaan screening:

Berdasarkan Tabel 1 dapat dilihat bahwa sebanyak 24,2\% dari 360 responden yang menjawab "tidak", artinya responden tersebut tidak pernah mengunjungi coffee shop pilihan mereka pada pertanyaan top of mind sebanyak minimal 3 kali kedatangan. Dari hasil ini dapat diasumsikan bahwa kecenderungan responden dalam menentukan coffee shop yang menjadi top of mind bukan merupakan coffee shop yang sudah dikunjungi. Jadi secara tidak langsung dapat diasumsikan adanya hubungan jawaban pertanyaan screening ini dengan kesesuaiannya pada jawaban top of mind. Responden yang memilih coffee shop sebagai top of mind -nya mungkin hanya merupakan merek yang hanya pernah dilihat atau didengar saja.

Angka 24,2\% ini mempunyai beberapa kemungkinan, yaitu frekuensi kunjungan hanya 1 sampai 2 kali dan tidak pernah sama sekali. Sehingga

Tabel 1. Cross-tabulation Top of Mind dan Screening Question

\begin{tabular}{lcccccccccc}
\hline & \multicolumn{2}{c}{ EXCELSO } & \multicolumn{2}{c}{ DOME } & \multicolumn{2}{c}{ COFFEE BEAN } & \multicolumn{2}{c}{ STARBUCKS } & \multicolumn{2}{c}{ TOTAL } \\
\cline { 2 - 11 } & JML & $\mathbf{\%}$ & JML & $\mathbf{\%}$ & JML & $\mathbf{\%}$ & JML & $\mathbf{\%}$ & JML & \% \\
\hline Tidak & 31 & 20.4 & 4 & 29 & 9 & 24.3 & 43 & 27.4 & 87 & 24.2 \\
Ya & 121 & 79.6 & 10 & 71 & 28 & 75.7 & 114 & 72.6 & 273 & 75.8 \\
\hline TOTAL & $\mathbf{1 5 2}$ & $\mathbf{1 0 0}$ & $\mathbf{1 4}$ & $\mathbf{1 0 0}$ & $\mathbf{3 7}$ & $\mathbf{1 0 0}$ & $\mathbf{1 5 7}$ & $\mathbf{1 0 0}$ & $\mathbf{3 6 0}$ & $\mathbf{1 0 0}$ \\
\hline
\end{tabular}

Sumber : Data primer, diolah 
responden ini dinilai tidak memenuhi syarat pengisian pertanyaan selanjutnya. Jadi, top of mind tidak boleh dianggap sebagai penentu dalam memperkirakan jumlah konsumen suatu coffee shop. Tetapi orang-orang dengan tipe seperti ini (top of mind tapi tidak pernah berkunjung) memiliki potensi untuk menjadi konsumen bahkan konsumen yang loyal dengan strategi-strategi tertentu.

\section{Kesadaran Merek - Dimensi Brand Recall}

Sesuai dengan yang tertera pada Tabel 2, mayoritas responden mampu menyebutkan 3 sampai 4 coffee shop, yaitu sebanyak 60,56\% dari total responden. Dari hasil kuisioner yang dikumpulkan, ketiga coffee shop yang banyak disebut berkisar antara Excelso, DOME, Coffee Bean dan Starbucks.

Dari data pada tabel 2, untuk responden yang dapat menyebutkan coffee shop 3 sampai dengan lebih dari 4, dapat diintepretasikan bahwa responden mempunyai pengetahuan dan pengenalan tentang coffee shop di Surabaya yang cukup baik. Dari hal tersebut, terdapat kemungkinan bahwa responden merupakan pengkonsumsi atau penikmat kopi. Dampak yang perlu diperhatikan oleh pihak pebisnis coffee shop yaitu bahwa responden hal ini mempunyai kesempatan atau peluang untuk berpindah dan mencoba coffee shop yang lain. Konsumen dengan karakteristik ini perlu mendapat perhatian yang lebih dari pihak manajemen, agar kemungkinan konsumen untuk mencoba coffee shop yang lain lebih kecil.

Tabel 2. Kesadaran Merek - Brand Recall
Di lain pihak, bagi responden yang menyebutkan coffee shop di luar merek Top of Mind yang disebut, dapat dikatakan memiliki peluang lebih kecil untuk berpindah dan mencoba coffee shop yang lain. Responden kelompok ini cenderung hanya bertindak berdasarkan apa yang mereka tahu dan ingat saja, sehingga semakin sedikit yang diingat maka semakin besar kemungkinan untuk berkunjung ke coffee shop tersebut. Dengan pelayanan dari pihak coffee sho yang lebih baik lagi, responden kelompok ini punya kemungkinan untuk menjadi repeated guest dan hal ini merupakan peluang yang bagus bagi pihak pebisnis coffee shop.

\section{Kesadaran Merek - Dimensi Brand Recognition}

Dapat dianalisis dari Tabel 3 bahwa dari keseluruhan responden, sebanyak 92,5\% dapat melengkapi huruf sesuai dengan pilihan coffee shop mereka pada pertanyaan top of mind. Ini menunjukkan bahwa responden yang memilih masing-masing coffee shop mengetahui benar merek tersebut, selain itu dapat diasumsikan bahwa merek top of mind yang responden sebutkan bukan sembarang sebut. Tetapi benar-benar responden memiliki kesadaran merek yang kuat tentang coffee shop tersebut. Sedangkan hasil sisanya yaitu sebanyak 7,5\% dapat diasumsikan bahwa kemungkinan responden hanya sebatas mengetahui dari mendengar saja.

Dari ketiga dimensi di atas, yang paling berperan dalam melihat kesadaran merek adalah top of mind karena top of mind merupakan tingkatan tertinggi dalam piramida kesadaran merek. Maka sesuai

\begin{tabular}{lccccccccc}
\hline & \multicolumn{2}{c}{ EXCELSO } & \multicolumn{2}{c}{ DOME } & \multicolumn{2}{c}{$\begin{array}{c}\text { COFFEE } \\
\text { BEAN }\end{array}$} & \multicolumn{2}{c}{ STARBUCKS } \\
\cline { 2 - 9 } & \multicolumn{2}{c}{ JML } & \% & JML & \% & JML & \% & JML & \% \\
\hline Responden menyebutkan 1 coffee shop & 18 & 11.84 & 0 & 0 & 0 & 0 & 8 & 5.10 \\
Responden menyebutkan 2 coffee shop & 34 & 22.37 & 3 & 21.43 & 3 & 8.11 & 25 & 15.92 \\
Responden menyebutkan 3 coffee shop & 48 & 31.58 & 3 & 21.43 & 14 & 37.84 & 45 & 28.66 \\
Responden menyebutkan 4 coffee shop & 33 & 21.71 & 4 & 28.57 & 14 & 37.84 & 57 & 36.31 \\
Responden menyebutkan>4 coffee shop & 19 & 12.5 & 4 & 28.57 & 6 & 16.22 & 22 & 14.01 \\
\hline
\end{tabular}

Sumber : Data primer, diolah

Tabel 3. Kesadaran Merek - Brand Recognition

\begin{tabular}{|c|c|c|c|c|c|c|c|c|c|c|}
\hline & \multicolumn{2}{|c|}{ EXCELSO } & \multicolumn{2}{|l|}{ DOME } & \multicolumn{2}{|c|}{ COFFEE BEAN } & \multicolumn{2}{|c|}{ STARBUCKS } & \multicolumn{2}{|c|}{ TOTAL } \\
\hline & JML & $\%$ & JML & $\%$ & JML & $\%$ & JML & $\%$ & JML & $\%$ \\
\hline Tidak & 18 & 11.8 & 0 & 0 & 4 & 10.8 & 5 & 3.2 & 27 & 25.84 \\
\hline Ya & 134 & 88.2 & 14 & 100 & 33 & 89.2 & 152 & 96.8 & 333 & 374.2 \\
\hline TOTAL & 152 & 100 & 14 & 100 & 37 & 100 & 157 & 100 & 360 & 400 \\
\hline
\end{tabular}

Sumber : Data primer, diolah 
dengan analisis top of mind di atas, Starbucks merupakan coffee shop utama dari berbagai coffee shop yang ada di dalam pikiran responden.

\section{Analisis Asosiasi Merek Coffee Shop di Surabaya}

Asosiasi Merek - Dimensi Kekuatan Merek (Brand Strength)

Dari hasil perhitungan, Excelso menjadi coffee shop yang mempunyai kekuatan merek paling positif, yaitu mencapai angka 84,05\%. Artinya Excelso mempunyai asosiasi paling positif dalam dimensi kekuatan merek.

Selanjutnya, dilihat dari setiap coffee shop, masing-masing coffee shop mempunyai asosiasi kekuatan merek yang berbeda-beda. Asosiasi tersebut menjadi modal yang potensial untuk membangun kekuatan merek itu sendiri. Untuk Excelso dan DOME, keduanya mencapai nilai tertinggi pada asosiasi "ada di hampir setiap shopping mall" dan "mempunyai image yang baik". Pada kedua asosiasi ini, kedua coffee shop tersebut mencapai angka diatas $90 \%$, artinya ini menjadi modal yang potensial untuk dipertahankan guna mencapai asosiasi merek yang kuat. Sedangkan untuk Coffee Bean dan
Starbucks, keduanya mempunyai nilai tertinggi pada asosiasi "mempunyai image yang baik" dan "harga mahal". Berbeda dengan halnya Excelso dan DOME, Coffee Bean dan Starbucks mempunyai asosiasi potensial yang berbeda.

\section{Asosiasi Merek - Dimensi Kesukaan Merek}

Untuk dimensi kesukaan merek secara keseluruhan, Coffee Bean yang mendapatkan asosiasi tentang kesukaan pada merek paling positif sebesar 90,54\%. Asosiasi ini merupakan nilai yang patut dipertahankan, karena berhubungan dengan sebanding tidaknya harga yang dibayarkan konsumen dan nilai yang diterima dari coffee shop tersebut.

Ditinjau dari masing-masing coffee shop, Excelso mencapai nilai yang cukup tinggi pada ketiga asosiasi kesukaan merek. Selain makanan dan minumannya enak dan penampilannya menarik, Excelso juga diasosiasikan menjadi tempat yang cocok untuk nongkrong dan meeting. Tetapi pihak Excelso diharapkan dapat memperbaiki porsi makanan sehingga dapat memberi kepuasan pada konsumennya. Karena dapat diasumsikan dari nilai yang yang didapat Excelso, konsumen kurang puas dengan porsi makanan/minuman Excelso.

Lain halnya dengan DOME yang hanya mem-

Tabel 4. Asosiasi Merek - Kekuatan Merek

\begin{tabular}{|c|c|c|c|c|c|c|c|c|}
\hline \multirow[t]{2}{*}{ KEKUATAN MEREK } & \multicolumn{2}{|c|}{ EXCELSO } & \multicolumn{2}{|l|}{ DOME } & \multicolumn{2}{|c|}{$\begin{array}{c}\text { COFFEE } \\
\text { BEAN }\end{array}$} & \multicolumn{2}{|c|}{ STARBUCKS } \\
\hline & JML & $\%$ & JML & $\%$ & JML & $\%$ & JML & $\%$ \\
\hline Total Responden & 152 & 100 & 14 & 100 & 37 & 100 & 157 & 100 \\
\hline Ada di hampir setiap shopping mall & 140 & 92.11 & 13 & 92.86 & 25 & 67.57 & 123 & 78.34 \\
\hline Mempunyai image yang baik & 146 & 96.05 & 13 & 92.86 & 35 & 94.59 & 153 & 97.45 \\
\hline Harga mahal & 116 & 76.32 & 11 & 78.57 & 26 & 70.27 & 137 & 87.26 \\
\hline Selalu padat pengunjung & 109 & 71.71 & 9 & 64.29 & 25 & 67.57 & 97 & 61.78 \\
\hline MEAN & & 84.05 & & 82.14 & & 75.00 & & 81.21 \\
\hline
\end{tabular}

Sumber : Data primer, diolah

Tabel 5. Asosiasi Merek - Kesukaan Merek

\begin{tabular}{|c|c|c|c|c|c|c|c|c|}
\hline \multirow[t]{2}{*}{ KESUKAAN MEREK } & \multicolumn{2}{|c|}{ EXCELSO } & \multicolumn{2}{|c|}{ DOME } & \multicolumn{2}{|c|}{$\begin{array}{l}\text { COFFEE } \\
\text { BEAN }\end{array}$} & \multicolumn{2}{|c|}{ STARBUCKS } \\
\hline & JML & $\%$ & JML & $\%$ & JML & $\%$ & JML & $\%$ \\
\hline Total Responden & 152 & 100 & 14 & 100 & 37 & 100 & 157 & 100 \\
\hline Makanan/minuman enak & 145 & 95.39 & 10 & 71.43 & 37 & 100 & 137 & 87.26 \\
\hline Penampilan makanan/minuman menarik & 137 & 90.13 & 11 & 78.57 & 35 & 94.59 & 149 & 94.9 \\
\hline Porsi makanan/minuman memuaskan & 100 & 65.79 & 10 & 71.43 & 26 & 70.27 & 97 & 61.78 \\
\hline $\begin{array}{l}\text { Tempat yang cocok untuk nongkrong dan } \\
\text { meeting }\end{array}$ & 144 & 94.74 & 14 & 100 & 36 & 97.3 & 150 & 95.54 \\
\hline MEAN & & 86.51 & & 80.36 & & 90.54 & & 84.87 \\
\hline
\end{tabular}

Sumber : Data primer, diolah 
peroleh jawaban positif dari konsumen sebagai tempat yang paling cocok untuk nongkrong dan meeting. Sedangkan untuk Coffee Bean, seperti halnya Excelso harus memperbaiki asosiasi porsi makanan yang dianggap kurang memuaskan.

Starbucks mencapai nilai 90\% lebih pada asosiasi "penampilan makanan/minuman menarik" dan "tempat yang cocok untuk nongkrong dan meeting". Agaknya pihak Starbucks harus memberikan perhatian khusus pada kesukaan merek ini, mengingat angka total yang dicapai Starbucks merupakan kedua terendah.

Asosiasi Merek - Dimensi Keunikan Merek
Apabila dilihat dari masing-masing coffee shop, keempatnya mempunyai keunggulan asosiasi keunikan merek yang berbeda-beda. Excelso mempunyai keunggulan pada asosiasi 'atmosfer yang santai dan kasual', sedangkan DOME diasosiasikan 'variasi minuman yang beraneka ragam' dan 'atmosfer yang santai dan kasual'. Bagi konsumen, pada asosiasi keunikan merek ini, DOME dinilai mempunyai lokasi yang kurang strategis. Bagi responden Coffee Bean, mereka sangat setuju mengasosiasikan Coffee Bean sebagai coffee shop yang mempunyai atmosfer paling santai dan kasual. Keunikan Coffee Bean ini mencapai angka 100\%.

Tabel 6. Asosiasi Merek - Keunikan Merek

\begin{tabular}{lccccccccc}
\hline \multirow{2}{*}{ KEUNIKAN MEREK } & \multicolumn{2}{l}{ EXCELSO } & \multicolumn{2}{c}{ DOME } & \multicolumn{2}{c}{ COFFEE BEAN } & \multicolumn{2}{c}{ STARBUCKS } \\
\cline { 2 - 10 } & JML & $\mathbf{\%}$ & JML & $\mathbf{\%}$ & JML & $\mathbf{\%}$ & JML & $\mathbf{\%}$ \\
\hline Total Responden & $\mathbf{1 5 2}$ & $\mathbf{1 0 0}$ & $\mathbf{1 4}$ & $\mathbf{1 0 0}$ & $\mathbf{3 7}$ & $\mathbf{1 0 0}$ & $\mathbf{1 5 7}$ & $\mathbf{1 0 0}$ \\
\hline Variasi minuman beranekaragam & 136 & 89.47 & 13 & 92.86 & 32 & 86.49 & 143 & 91.08 \\
Atmosfer yang santai dan kasual & 138 & 90.79 & 13 & 92.86 & 37 & 100 & 151 & 96.18 \\
Lokasi yang strategis & 135 & 88.82 & 12 & 85.71 & 31 & 83.78 & 149 & 94.9 \\
\hline MEAN & & $\mathbf{8 9 . 6 9}$ & & $\mathbf{9 0 . 4 8}$ & & $\mathbf{9 0 . 0 9}$ & $\mathbf{9 4 . 0 6}$ \\
\hline
\end{tabular}

Sumber : Data primer, diolah

Tabel 7. Rata - rata Asosiasi Merek

\begin{tabular}{lcccc}
\hline \multirow{2}{*}{ ASOSIASI MEREK } & EXCELSO & DOME & COFFEE BEAN & STARBUCKS \\
\cline { 2 - 5 } & $\mathbf{\%}$ & $\mathbf{\%}$ & $\mathbf{\%}$ & $\mathbf{\%}$ \\
\hline Rata-rata kekuatan merek & 84.05 & 82.14 & 75.00 & 81.21 \\
Rata-rata kesukaan merek & 86.51 & 80.36 & 90.54 & 84.87 \\
Rata-rata keunikan merek & 89.69 & 90.48 & 90.09 & 94.06 \\
\hline TOTAL MEAN & $\mathbf{8 6 . 7 5}$ & $\mathbf{8 4 . 3 3}$ & $\mathbf{8 5 . 2 1}$ & $\mathbf{8 6 . 7 1}$ \\
\hline
\end{tabular}

Sumber : Data primer, diolah

Tabel 8. Kesan Kualitas - Produk

\begin{tabular}{|c|c|c|c|c|c|c|c|c|}
\hline \multirow[t]{2}{*}{ KESAN KUALITAS } & \multicolumn{2}{|c|}{ EXCELSO } & \multicolumn{2}{|c|}{ DOME } & \multicolumn{2}{|c|}{$\begin{array}{c}\text { COFFEE } \\
\text { BEAN }\end{array}$} & \multicolumn{2}{|c|}{ STARBUCKS } \\
\hline & JML & $\%$ & JML & $\%$ & JML & $\%$ & JML & $\%$ \\
\hline \multicolumn{9}{|l|}{ Produk } \\
\hline Total responden & 90 & 100 & 90 & 100 & 90 & 100 & 90 & 100 \\
\hline Rasa makanan dan minuman enak & 81 & 90 & 80 & 88.89 & 86 & 95.56 & 87 & 96.67 \\
\hline Kemasan dan penyajian produk menarik & 83 & 92.22 & 82 & 91.11 & 85 & 94.44 & 87 & 96.67 \\
\hline Produk yang disajikan sesuai dengan menu & 81 & 90 & 85 & 94.44 & 85 & 94.44 & 86 & 95.56 \\
\hline Porsi yang diberikan sesuai dengan menu & 65 & 72.22 & 72 & 80 & 74 & 82.22 & 72 & 80 \\
\hline Kualitas produk konsisten & 75 & 83.33 & 73 & 81.11 & 79 & 87.78 & 67 & 74.44 \\
\hline Pelayanan produk yang diberikan memuaskan & 83 & 92.22 & 79 & 87.78 & 82 & 91.11 & 86 & 95.56 \\
\hline Kualitas produk secara keseluruhan bagus & 87 & 96.67 & 76 & 84.44 & 84 & 93.33 & 87 & 96.67 \\
\hline MEAN & & 88.1 & & 86.83 & & 91.27 & & 90.79 \\
\hline
\end{tabular}

Sumber : Data primer, diolah 
Starbucks mencapai rata-rata 90\% lebih pada ketiga asosiasi keunikan merek yang sehingga membuat Starbucks menjadi coffee shop yang paling unik dibandingkan dengan coffee shop lainnya. Keunikan ini membuka peluang bagi responden tetap untuk menjadi konsumen Starbucks bahkan sulit berpindah ke coffee shop lain.

\section{Analisis Keseluruhan Asosiasi Merek}

Dari tabel 7 dapat dianalisis secara keseluruhan bahwa Excelso merupakan coffee shop yang mempunyai asosiasi merek paling positif, dengan total mean $86,75 \%$. Positif berarti atribut yang diberikan responden kepada suatu merek dinilai sangat baik, dan semakin banyak. Dampaknya adalah semakin positif dan kuat image merek tersebut. Tetapi JML ini mempunyai selisih yang sangat kecil dibandingkan dengan peringkat keduanya yaitu Starbucks dengan selisih nilai $0.04 \%$. Angka ini menunjukkan bahwa Starbucks merupakan pesaing utama bagi Excelso untuk memiliki asosiasi merek yang paling positif, mengingat keduanya mempunyai responden top of mind yang cukup banyak juga.

\section{Analisis Kesan Kualitas Coffee Shop di Surabaya}

\section{$\underline{\text { Kesan Kualitas - Dimensi Produk }}$}

Hasil analisis kesan kualitas pada sub-dimensi produk ini menunjukkan Coffee Bean yang mempunyai kesan kualitas produk yang paling baik dibandingkan dengan ketiga coffee shop lain. Sedangkan Excelso, Coffee Bean dan Starbucks mempunyai kekuatan kesan kualitas produk yang sama dalam hal ini, yaitu mengenai rasa, kemasan, dan penyajian makanan/minuman secara keseluruhan. Ketiga coffee shop tersebut saling bersaing pada kelima indikator ini. Jadi, pihak manajemen sebaiknya mencari peluang indikator lain untuk lebih ditingkatkan.

Kesan Kualitas - Dimensi Jasa

Secara keseluruhan, Starbucks merupakan coffee

Tabel 9. Kesan Kualitas - Jasa

\begin{tabular}{|c|c|c|c|c|c|c|c|c|}
\hline \multirow{2}{*}{ KESAN KUALITAS } & \multicolumn{2}{|c|}{ EXCELSO } & \multicolumn{2}{|c|}{ DOME } & \multicolumn{2}{|c|}{$\begin{array}{l}\text { COFFEE } \\
\text { BEAN }\end{array}$} & \multicolumn{2}{|c|}{ STARBUCKS } \\
\hline & JML & $\%$ & JML & $\%$ & JML & $\%$ & JML & $\%$ \\
\hline \multicolumn{9}{|l|}{ Jasa / Servis } \\
\hline Total responden & 90 & 100 & 90 & 100 & 90 & 100 & 90 & 100 \\
\hline Karyawan memberikan informasi yang tepat & 81 & 90 & 73 & 81.11 & 79 & 87.78 & 79 & 87.78 \\
\hline Karyawan siap menanggapi permintaan konsumen & 76 & 84.44 & 70 & 77.78 & 77 & 85.56 & 81 & 90 \\
\hline $\begin{array}{l}\text { Selalu ada staf yang menyambut dan mempersilakan } \\
\text { konsumen yang baru }\end{array}$ & 76 & 84.44 & 70 & 77.78 & 60 & 66.67 & 57 & 63.33 \\
\hline $\begin{array}{l}\text { Keramahtamahan karyawan konsisten pada setiap } \\
\text { konsumen }\end{array}$ & 74 & 82.22 & 68 & 75.56 & 75 & 83.33 & 73 & 81.11 \\
\hline $\begin{array}{l}\text { Karyawan memiliki pengetahuan yang baik tentang } \\
\text { produk dan jasa yang dijual }\end{array}$ & 75 & 83.33 & 78 & 86.67 & 69 & 76.67 & 80 & 88.89 \\
\hline $\begin{array}{l}\text { Karyawan peduli dalam mengatasi kesulitan setiap } \\
\text { konsumen }\end{array}$ & 65 & 72.22 & 66 & 73.33 & 71 & 78.89 & 64 & 71.11 \\
\hline $\begin{array}{l}\text { Karyawan memperhatikan permintaan setiap } \\
\text { konsumen }\end{array}$ & 73 & 81.11 & 77 & 85.56 & 80 & 88.89 & 64 & 71.11 \\
\hline Penampilan karyawan rapi & 87 & 96.67 & 83 & 92.22 & 82 & 91.11 & 87 & 96.67 \\
\hline Pesanan dilayani dengan cepat & 58 & 64.44 & 62 & 68.89 & 71 & 78.89 & 73 & 81.11 \\
\hline $\begin{array}{l}\text { Penyajian makanan tepat sesuai yang dipesan oleh } \\
\text { pengunjung }\end{array}$ & 85 & 94.44 & 83 & 92.22 & 84 & 93.33 & 83 & 92.22 \\
\hline Desain interior yang menarik & 70 & 77.78 & 73 & 81.11 & 83 & 92.22 & 80 & 88.89 \\
\hline Fasilitas yang memadai (toilet, musik) & 40 & 44.44 & 46 & 51.11 & 65 & 72.22 & 73 & 81.11 \\
\hline Tempat bersih & 84 & 93.33 & 86 & 95.56 & 84 & 93.33 & 85 & 94.44 \\
\hline Ruangan luas & 54 & 60 & 55 & 61.11 & 69 & 76.67 & 70 & 77.78 \\
\hline Lay-out meja dan kursi tertata rapi & 82 & 91.11 & 85 & 94.44 & 75 & 83.33 & 86 & 95.56 \\
\hline MEAN & & 80 & & 79.63 & & 83.26 & & 84.07 \\
\hline
\end{tabular}

Sumber : Data primer, diolah 
shop yang mendapatkan penilaian tertinggi dari konsumennya tentang kesan kualitas sub-dimensi jasa dengan rata-rata prosentase keseluruhan indikatornya adalah 84,07\%. Dapat diartikan bahwa Starbucks mampu memberikan pelayanan/servis yang terbaik kepada konsumennya dibandingkan dengan ketiga coffee shop yang lain. Sangat ironis jika dilihat dari bentuk servisnya, seperti yang telah disebutkan diatas Coffee Bean dan Starbucks dengan konsep self-service justru menduduki tempat pertama dan kedua, sedangkan Excelso dan DOME dengan konsep table-service menduduki tempat kedua terakhir.

\section{Analisis Keseluruhan Kesan Kualitas}

Dengan demikian, hasil penilaian kesan kualitas secara keseluruhan (baik produk maupun jasa) dapat dilihat pada Tabel 10 :

Dari tabel 11, terlihat jelas Starbucks mengungguli ketiga coffee shop lain dalam penilaian konsumen tentang kesan kualitas yang dimilikinya dengan prosentase $87,3 \%$, artinya Starbucks dinilai paling mampu memberikan produk dan jasa yang sesuai dengan apa yang diharapkan konsumennya, sehingga kesan kualitas yang dimilikinya adalah yang terbaik dan paling positif. Tetapi prosentasenya tidak jauh berbeda dengan Coffee Bean dan kedua coffee shop yang lainnya.Berarti Starbucks harus waspada dan berusaha mempertahankan posisinya di mata konsumen. Mengingat Starbucks mempunyai asosiasi sebagai harga termahal, maka ini harus berjalan seiiring dengan kesan kualitas yang diberikan, agar konsumen merasa harga yang dibayarkan sebanding dengan nilai yang didapat (meliputi kualitas produk dan jasa).

\section{Analisis Kesetiaan Merek Coffee Shop di Sura- baya}

\section{Kesetiaan Merek - Dimensi Friend of Brand Buyer}

Tabel 11 merupakan perhitungan rata-rata prosentase dari keempat coffee shop terhadap masingmasing indikator variabel ini :

Starbucks mempunyai prosentase tertinggi pada kedua indikator pertanyaan, yakni $62,22 \%$ dan 93,33\%. Dan keduanya pun boleh dikatakan terpaut cukup jauh dari ketiga coffee shop lainnya, sehingga 77,78\% konsumen Starbucks menyukainya karena telah mengalami pengalaman-pengalaman yang baik saat berkunjung (kesan kualitas dan asosiasi yang positif) dan perasaan emosi yang terkait.

Kesetiaan Merek-Dimensi Committed Buyer (Pembeli komit)

Dari tabel 12 dapat dilihat bahwa Starbucks menempati peringkat teratas pada empat pertanyaan dan Coffee bean pada satu pertanyaan sisanya. Yang menjadi sorotan adalah pertanyaan terakhir yang menanyakan komitmen konsumen untuk tetap setia pada coffee shop pilihan jika dihadapkan pada godaan dari coffee shop yang lain, ternyata hasilnya dibawah 30\% konsumen yang tetap dengan komitmen mereka untuk tidak berpindah. Ini dapat diasumsikan bahwa promosi merupakan daya tarik yang kuat dan senjata yang cukup ampuh dalam persaingan untuk mendapatkan konsumen. Maka

Tabel 10. Rata - rata Kesan Kualitas

\begin{tabular}{lcccc}
\hline \multirow{2}{*}{ KESAN KUALITAS } & EXCELSO & DOME & COFFEE BEAN & \multicolumn{1}{c}{ STARBUCKS } \\
\cline { 2 - 5 } & $\mathbf{\%}$ & $\mathbf{\%}$ & $\mathbf{\%}$ & $\mathbf{\%}$ \\
\hline Rata-rata kesan kualitas produk & 88.1 & 86.83 & 91.27 & 90.79 \\
Rata-rata kesan kualitas jasa & 80 & 79.63 & 83.26 & 84.07 \\
\hline TOTAL MEAN & $\mathbf{8 4 . 0 5}$ & $\mathbf{8 3 . 2 3}$ & $\mathbf{8 7 . 2 6}$ & $\mathbf{8 7 . 4 3}$ \\
\hline
\end{tabular}

Sumber : Data primer, diolah

Tabel 11. Kesetiaan Merek - Friend of Brand Buyer

\begin{tabular}{|c|c|c|c|c|c|c|c|c|}
\hline \multirow[t]{2}{*}{ KESETIAAN MEREK } & \multicolumn{2}{|c|}{ EXCELSO } & \multicolumn{6}{|c|}{ COFFEE } \\
\hline & JML & $\%$ & JML & $\%$ & JML & $\%$ & JML & $\%$ \\
\hline Total responden & 90 & 100 & 90 & 100 & 90 & 100 & 90 & 100 \\
\hline Pilihan utama dibandingkan coffee shop lain & 47 & 52.22 & 29 & 32.22 & 46 & 51.11 & 56 & 62.22 \\
\hline Puas pada setiap kedatangan Anda & 71 & 78.89 & 65 & 72.22 & 75 & 83.33 & 84 & 93.33 \\
\hline MEAI & & 65.56 & & 52.22 & & 67.22 & & 77.78 \\
\hline
\end{tabular}

Sumber : Data primer, diolah 
perusahaan harus mempertimbangkan cara yang tepat untuk menutup lubang ini.

Akhirnya, 75,78\% konsumen Starbucks tergolong konsumen sudah memiliki keterikatan emosional dan berkomitmen. Hal ini sangat mempengaruhi nilai dari Starbucks itu sendiri, dalam arti, merek Starbucks dapat memberikan kepuasan psikologis bagi konsumennya. Hal ini bisa disebabkan oleh kesan kualitas dan asosiasi yang dimiliki Starbucks cukup bagus, contohnya menjadi konsumen Starbucks memberikan prestige dan kebanggaan tersendiri karena harga minuman dan makanannya tergolong mahal sehingga hanya orang berkelas atas yang bisa menikmatinya.

\section{Analisis Keseluruhan Kesetiaan Merek}

Tabel 13 merupakan perbandingan akumulasi jumlah dan prosentase setiap coffee shop:

Dari tabel 13 dapat terlihat jelas bahwa Starbucks yang memiliki konsumen yang tergolong loyal, paling banyak dibandingkan dengan ketiga coffee shop lainnya, yaitu $76.78 \%$. Kesetiaan merek ini merupakan hasil dari ketiga variabel yang lain (kesadaran merek, asosiasi merek dan kesan kualitas). Jadi saat konsumen sudah mengenal suatu coffee shop dengan asosiasi yang positif, dan memiliki kesan kualitas yang baik pada saat berkunjung, maka akan terbentuk loyalitas konsumen tersebut kepada coffee shop tersebut. Jadi, Starbucks dapat sedikit berbangga dengan perbedaan angka yang cukup jauh dengan ketiga coffee shop lainnya. Ini berarti Starbucks dinilai berhasil dalam mempertahankan kesetiaan konsumen lamanya dan kemungkinan untuk berpindah ke coffee shop yang lain kecil.

\section{Analisis Keseluruhan Ekuitas Merek Coffee Shop di Surabaya}

Dari tabel 14, Starbucks menjadi coffee shop pilihan responden yang memiliki ekuitas merek paling kuat dengan hasil 73,63\%. Dihubungkan dengan hasil penelitian sebelumnya yang menyatakan bahwa Starbucks termasuk dalam daftar Best Brand Award secara internasional, Starbucks juga menjadi pilihan masyarakat Surabaya sebagai Best Brand dalam kategori coffee shop. Artinya, Starbucks dianggap berhasil dalam membangun merek yang kuat, baik dalam produk, servis dan konsumen.

Dengan demikian, Starbucks diasumsikan berhasil dalam :

1. Memikat konsumen baru dan merangkul kembali konsumen lama serta menghilangkan keraguan konsumen terhadap kualitas merek.

2. Mengurangi keinginan konsumennya untuk mencoba merek-merek lain.

Tabel 12. Kesetiaan Merek - Committed Buyer

\begin{tabular}{|c|c|c|c|c|c|c|c|c|}
\hline \multirow{2}{*}{ KESETIAAN MEREK } & \multicolumn{2}{|c|}{ EXCELSO } & \multicolumn{2}{|c|}{ DOME } & \multicolumn{2}{|c|}{$\begin{array}{l}\text { COFFEE } \\
\text { BEAN }\end{array}$} & \multicolumn{2}{|c|}{ STARBUCKS } \\
\hline & JML & $\%$ & JML & $\%$ & JML & $\%$ & JML & $\%$ \\
\hline \begin{tabular}{lc|} 
Total responden \\
\end{tabular} & 90 & 100 & 90 & 100 & 90 & 100 & 90 & 100 \\
\hline $\begin{array}{l}\text { Akan kembali untuk kedatangan } \\
\text { selanjutnya }\end{array}$ & 75 & 83.33 & 73 & 81.11 & 72 & 80 & 84 & 93.33 \\
\hline Merekomendasikan pada orang lain & 68 & 75.56 & 64 & 71.11 & 68 & 75.56 & 76 & 84.44 \\
\hline Akan mengajak orang lain datang & 73 & 81.11 & 64 & 71.11 & 67 & 74.44 & 77 & 85.56 \\
\hline Bersedia membeli produk yang lain & 73 & 81.11 & 73 & 81.11 & 69 & 76.67 & 82 & 91.11 \\
\hline $\begin{array}{l}\text { Tidak akan berpindah ke coffee shop lain } \\
\text { meskipun ada tawaran/promosi }\end{array}$ & 14 & 15.56 & 8 & 8.889 & 26 & 28.89 & 22 & 24.44 \\
\hline MEAN & & 67.33 & & 62.67 & & 67.11 & & 75.78 \\
\hline
\end{tabular}

Sumber : Data primer, diolah

Tabel 13. Rata - rata Kesetiaan Merek

\begin{tabular}{|c|c|c|c|c|c|c|c|c|}
\hline \multirow{2}{*}{ KESETIAAN MEREK } & \multicolumn{2}{|c|}{ EXCELSO } & \multicolumn{2}{|c|}{ DOME } & \multicolumn{2}{|c|}{$\begin{array}{c}\text { COFFEE } \\
\text { BEAN }\end{array}$} & \multicolumn{2}{|c|}{ STARBUCKS } \\
\hline & JML & $\%$ & JML & $\%$ & JML & $\%$ & JML & $\%$ \\
\hline Rata-rata pembeli yang menyukai merek & & 65.56 & & 52.22 & & 67.22 & & 77.78 \\
\hline Rata-rata pembeli komit & & 67.33 & & 62.67 & & 67.11 & & 75.78 \\
\hline TOTAL MEAN & & 66.44 & & 57.44 & & 67.17 & & 76.78 \\
\hline
\end{tabular}

Sumber : Data primer, diolah 
Tabel 14. Ekuitas Merek

\begin{tabular}{lcccc}
\hline \multicolumn{5}{c}{ EKUITAS MEREK } \\
\hline \multirow{2}{*}{ VARIABEL } & \multicolumn{4}{c}{ COFFEE SHOP } \\
\cline { 2 - 5 } & EXCELSO & DOME & COFFEE BEAN & STARBUCKS \\
\hline Kesadaran merek & 42.22 & 3.89 & 10.28 & 43.61 \\
Asosiasi merek & 86.75 & 84.33 & 85.21 & 86.71 \\
Kesan kualitas & 84.05 & 83.23 & 87.26 & 87.43 \\
Kesetiaan merek & 66.44 & 57.44 & 67.17 & 76.78 \\
\hline \multicolumn{1}{c}{ MEAN } & $\mathbf{6 9 . 8 7}$ & $\mathbf{5 7 . 2 2}$ & $\mathbf{6 2 . 4 8}$ & $\mathbf{7 3 . 6 3}$ \\
\hline
\end{tabular}

Sumber : Data primer, diolah

3. Memberikan keuntungan kompetitif yang sering kali memberikan rintangan nyata terhadap para kompetitor.

Jika dilihat secara sekilas, Excelso dapat dianggap sebagai pesaing utama Starbucks karena pada variabel top of mind, jumlah responden yang mengenal Excelso tidak jauh berbeda dengan Starbucks. Tetapi apabila diamati secara seksama, pesaing utama Starbucks adalah Coffee Bean. Hal ini dapat dilihat dari prosentase Coffee Bean yang hanya berbeda sedikit dengan Starbucks dibandingkan Excelso terhadap Starbucks.

\section{KESIMPULAN DAN SARAN}

1. Kesimpulan mengenai kesadaran merek (brand awareness)

Starbucks merupakan coffee shop yang menjadi the top of mind - Brand Awareness. Dengan demikian, Starbucks merupakan coffee shop utama dari berbagai coffee shop yang diingat pertama kali oleh responden.

2. Kesimpulan mengenai asosiasi merek (brand associations)

Excelso merupakan coffee shop yang memiliki asosiasi merek yang paling positif.

Hal ini berarti atribut yang diberikan responden kepada suatu merek dinilai sangat baik dan semakin banyak, dampaknya adalah semakin positif dan kuat image yang terbangun pada merek tersebut. Excelso yang merupakan bisnis lokal dapat mempunyai asosiasi merek yang lebih positif dibandingkan dengan Starbucks yang merupakan bisnis skala internasional.

3. Kesimpulan mengenai kesan kualitas (perceived quality)

Starbucks merupakan coffee shop yang menjadi the best of Perceived Quality, artinya Starbucks dinilai paling mampu memberikan produk dan jasa yang sesuai dengan apa yang diharapkan konsumennya.

4. Kesimpulan mengenai loyalitas merek (brand loyalty)
Starbucks merupakan coffee shop yang menjadi the strongest of Brand Loyalty. Hal ini ditunjukkan bahwa mayoritas konsumen Starbucks bersedia untuk datang kembali, merekomendasikan kepada orang lain, mengajak orang lain dan membeli produk Starbucks lebih.

Selanjutnya, berdasarkan hasil penelitian di atas, penulis memberikan beberapa saran khususnya bagi masing-masing coffee shop antara lain:

1. Bagi Excelso

Dari hasil penelitian ini, didapati bahwa hasil terendah Excelso ada pada variabel kesan kualitas yaitu masalah fasilitas. Maka hal tersebut perlu menjadi perhatian khusus. Dengan penyediaan fasilitas yang memadai, akan meningkatkan kesan kualitas Excelso itu sendiri.

2. Bagi DOME

DOME termasuk coffee shop yang mempunyai outlet hampir disetiap shopping mall, tetapi keberadaannya masih belum mendapat perhatian dari masyarakat, khususnya Surabaya. Meskipun bisnis ini dimulai bersamaan dengan masuknya Starbucks dan Coffee Bean tetapi DOME tidak dapat menyaingi tingkat ekuitas merek kedua coffee shop tersebut.

3. Bagi Coffee Bean \& Tea Leaf

Saran untuk pihak Coffee Bean, penambahan jumlah gerai dirasakan perlu, karena hal itu sangat berpengaruh bagi masyarakat. Semakin banyak gerai yang ada, akan semakin tinggi tingkat kesadaran masyarakat akan coffee shop tersebut.

4. Bagi Starbucks Coffee

Bagi Starbucks yang sudah mencapai tingkat ekuitas merek terbaik dibandingkan dengan coffee shop yang lain, hal terpenting adalah mempertahankan dan meningkatkan kinerja secara keseluruhan. Mengingat jumlah konsumen loyalnya tergolong tinggi, diharapkan Starbucks mampu mempertahankan kedudukannya sebagai coffee shop dengan ekuitas merek yang terbaik. 
5. Bagi penelitian selanjutnya:

Penelitian ini dilakukan dengan metode kuantitatif yang hanya mengukur ekuitas merek dari sudut pandang konsumen saja. Maka, diharapkan penelitian tentang ekuitas merek selanjutnya dapat mencakup 2 sisi, baik itu konsumen maupun pebisnis/perusahaannya (seperti, dengan mempertimbangkan pendapatan dan manajemen perusahaan). Dengan gabungan metode kualitatif dan kuantitatif diharapkan penelitian selanjutnya mampu mengukur ekuitas merek lebih akurat.

\section{DAFTAR REFERENSI}

Aaker, D. A. (1996). Building strong brands. New York: The Free Press.

(1991). Managing brand equity. New York: The Free Press.

(2001). Strategic market management. USA : John Wiley \& Sons, INC.

Dalrymple, J. and Parsons, J. (2000). Marketing management $\left(7^{\text {th }}\right.$ edn). USA. John Wiley \& Sons. INC.

Ford, K. (2005). Brands laid bare. London: John Wiley \& Sons, Ltd.

Frampton, J. (2006). Research economy Interbrand's best global brands 2006. New York. Business Week and Interbrand.

Keller, K. L. (2003). Building, measuring and managing brand equity ( $\left.2^{\text {nd }} e d n\right)$, New Jersey: Prentice Hall.
Kotler, P. (1997). Marketing management: Analysis, planning, implementation and control $\left(9^{\text {th }}\right.$ edn), New Jersey: Prentice Hall.

Kotler, P. and Armstrong, G. (2006) Principles of marketing (11 ${ }^{\text {th }}$ edn), New Jersey: Prentice Hall.

Levine, S. K., and Berenson. (2002). Statistics for managers $\left(3^{r d} e d n\right)$, New Jersey: Prentice Hall.

Malhotra, N.K. (1996). Marketing research: An applied orientation (2nd edn), New Jersey: Prentice Hall

MBA Companion in Marketing. (1999) Mastering marketing: Prentice Hall.

Panneerselvam. R.(2005). Research methodology. New Delhi: Prentice Hall.

Soehadi, A. (2005). Effective branding, Bandung: Quantum.

Suliyanto. (2005). Analisis data dalam aplikasi pemasaran, Bogor: Ghalia Indonesia.

Susanto, A.B and Wijanarko, H. (2004). Power branding, Bandung : Quantum.

SWA Majalah edisi Maret. 2005.

SWA Majalah edisi April. 2007.

Warren, K. (1995). Global marketing management ( $5^{\text {th }}$ edn). New Jersey: Prentice Hall. 